\title{
Endothelial cells, tissue factor and infectious diseases
}

L.M. Lopes-Bezerra ${ }^{1}$ and S.G. Filler ${ }^{2}$

\section{Correspondence}

L.M. Lopes Bezerra

Laboratório de Biologia Celular e

Bioquímica de Fungos Patogênicos

Instituto de Biologia, UERJ

Rua São Francisco Xavier, 524

PHLC 204

20550-013 Rio de Janeiro, RJ

Brasil

E-mail: leila@uerj.br

Presented at SIMEC 2002

(International Symposium

on Extracellular Matrix),

Angra dos Reis, RJ, Brazil,

October 7-10, 2002.

L.M. Lopes-Bezerra was supported by CAPES (BEX 0165/01-8).

Received January 14, 2003

Accepted March 26, 2003
${ }^{1}$ Departamento de Biologia Celular e Genética, Instituto de Biologia Roberto Alcântara Gomes, Universidade do Estado do Rio de Janeiro, Rio de Janeiro, RJ, Brasil

2Department of Medicine, Harbor-UCLA Research and Education Institute, Torrance, CA, USA

Abstract

Tissue factor is a transmembrane procoagulant glycoprotein and a member of the cytokine receptor superfamily. It activates the extrinsic coagulation pathway, and induces the formation of a fibrin clot. Tissue factor is important for both normal homeostasis and the development of many thrombotic diseases. A wide variety of cells are able to synthesize and express tissue factor, including monocytes, granulocytes, platelets and endothelial cells. Tissue factor expression can be induced by cell surface components of pathogenic microorganisms, proinflammatory cytokines and membrane microparticles released from activated host cells. Tissue factor plays an important role in initiating thrombosis associated with inflammation during infection, sepsis, and organ transplant rejection. Recent findings suggest that tissue factor can also function as a receptor and thus may be important in cell signaling. The present minireview will focus on the role of tissue factor in the pathogenesis of septic shock, infectious endocarditis and invasive aspergillosis, as determined by both in vivo and in vitro models.

\section{The structure and location of tissue factor}

Tissue factor, also known as thromboplastin or CD142 (rarely as coagulation factor III), is a cell surface glycoprotein synthesized and expressed by a wide variety of cells (1-3). Tissue factor triggers the extrinsic coagulation pathway, plays a key role in homeostasis and in several thrombotic diseases, and is also involved in cell signaling (4-10). Tissue factor is a glycosylated membrane protein that consists of a single polypeptide chain of 263 amino acids with an apparent molecular mass of $46 \mathrm{kDa}$, as determined by
Key words

- Tissue factor

- Endothelial cell

- Fungus

- Infectious diseases

- Procoagulant activity

.....................
SDS-PAGE electrophoresis (5,11-14). Glycosylation does not appear to be important for tissue factor function as the recombinant nonglycosylated protein retains procoagulant activity (12). Tissue factor is a type I integral membrane protein. It has three domains: an extracellular domain, a single transmembrane domain, and a short cytoplasmic domain. The binding site for factor VII is located in the extracellular domain $(5,15)$.

Tissue factor is expressed by a diversity of cells such as smooth muscle cells, fibroblasts, monocytes, lymphocytes, granulocytes, platelets and endothelial cells $(1,3)$. Smooth muscle cells and fibroblasts express 
tissue factor constitutively (1). Following tissue injury, these cells come in contact with the bloodstream, and rapidly initiate the coagulation cascade. Myeloid cells and endothelial cells only express tissue factor when they are stimulated (16-19). They can be activated by proinflammatory cytokines, bacterial lipopolysaccharide (LPS), and some microorganisms $(16,20-22)$. The expression of active tissue factor on the cell surface requires at least $2 \mathrm{~h}$ in cultured cells (16). Activated cells can also release membrane microparticles into the circulation. These microparticles also contain tissue factor on their surface (7). However, the presence of tissue factor-containing microparticles in the circulation does not correlate with in vivo markers of coagulation, suggesting that tissue factor may play a role in another process, such as signaling or angiogenesis (23).

Tissue factor may also be present on the surface of endothelial cells, yet be inactive.

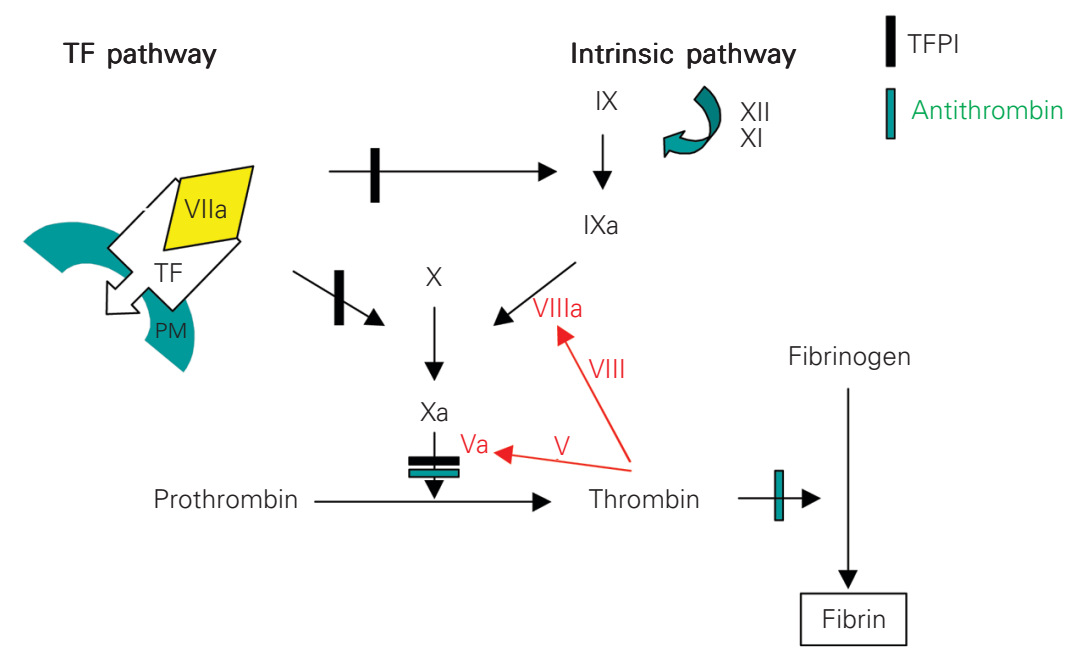

Figure 1. Scheme of the coagulation mechanism showing the main steps of the extrinsic coagulation pathway (tissue factor (TF) pathway) that is reported to be the primary trigger of clotting in vivo. The extracellular domain of TF binds native factor VII. Activation of factor VIla after complex formation with TF is followed by the conversion of factor $X$ to factor $X$ a. Both the intrinsic and the extrinsic pathways converge at the conversion of factor $X$ to factor $\mathrm{Xa}$, which yields thrombin. Thrombin promotes its own formation by a positive feedback mechanism through activation of factor $\mathrm{V}$ and factor VIII. Two additional endogenous inhibitory mechanisms include antithrombin (which binds unfractionated and low molecular weight heparin and pentasaccharide to inhibit factor Ila and factor Xa) and TF pathway inhibitor (TFPI) which blocks the formation of factor Xa. Reproduced with permission from Ref. 7. $\mathrm{PM}=$ plasma membrane.
This encrypted form of tissue factor is located mainly in caveolae of the endothelial cells (7). Encrypted tissue factor is capable of binding factor VIIa, but the complex remains catalytically inactive and incapable of initiating coagulation (24-26). Thus, encryption seems to prevent unwanted activation of intravascular thrombosis. The mechanism by which tissue factor is encrypted is still incompletely understood.

\section{The extrinsic coagulation cascade}

The initiation of coagulation following tissue injury requires the exposure of tissue factor to the bloodstream. Tissue factor then binds factor VII/factor VIIa that circulates in the blood (27). The tissue factor/factor VIIa complex activates both factor IX and factor X, thus leading to the sequential conversion of the blood clotting proenzymes to enzymes and the generation of a fibrin clot (Figure 1). The tissue factor or extrinsic pathway is linked to the intrinsic pathway by the activation of factor VIII and factor IX, which mediates thrombus propagation and extension. Thus, tissue factor plays a pivotal role in coagulation by initiating and propagating thrombus formation.

\section{Anticoagulant properties of normal endothelium}

Under normal conditions, endothelial cells prevent the activation of the coagulation cascade by expressing several surface molecules with anticoagulant properties (28). The most important homeostatic mechanisms that inhibit coagulation are: 1) the antithrombin III-heparin sulfate system, which inhibits thrombin and factor $\mathrm{Xa}$; 2) tissue factor protease inhibitor, which is composed of three Kunitz-type protease inhibitor domains, and directly inhibits factor $\mathrm{Xa}$ and mediates a negative feedback on tissue factor expression and factor VIIa $(29,30)$, and $3)$ the protein $\mathrm{C}$ pathway $(31,32)$. The pro- 
tein $\mathrm{C}$ pathway is activated when thrombin binds to the endothelial surface protein thrombomodulin (or CD141) and is facilitated by the transmembrane endothelial protein $\mathrm{C}$ receptor (33). In sepsis, endothelial damage and the presence of proinflammatory stimuli (e.g., TNF- $\alpha$, endotoxin) down-regulate both thrombomodulin and endothelial protein $\mathrm{C}$ receptor, thereby promoting intravascular coagulation. The molecular links between inflammation and coagulation are unquestionable. Inflammation promotes coagulation by leading to intravascular tissue factor expression and down-regulation of the fibrinolytic and protein $\mathrm{C}$ anticoagulant pathways. Protein $\mathrm{C}$ and antithrombin III are quickly depleted in sepsis as the body attempts to reestablish equilibrium (6). In fact, the level of circulating protein $\mathrm{C}$ is inversely related to mortality in patients with severe sepsis.

\section{Tissue factor, endothelial cells and infectious diseases}

Septic shock is a major health problem. It is the leading cause of death in intensive care units. Early studies of septic shock focused on inflammation as the dominant process causing vascular endothelial injury and the so-called sepsis cascade. However, given the universal failure of specific anti-inflammatory therapies in clinical trials of septic patients, a search for a more complex and multifactorial pathogenesis was undertaken (34). The new paradigm that has emerged from those investigations, which has radically changed the view of sepsis, is the current understanding that the disease process is caused by a loss of homeostasis between inflammation, coagulation, and fibrinolysis (35-38). This new paradigm is supported by the recent finding that recombinant activated protein $\mathrm{C}$ significantly reduces mortality in patients with sepsis (39).

Bacterial LPS and the inflammatory cytokines, TNF- $\alpha$ and interleukin-1, have been shown to be important mediators of septic shock (40). One mechanism by which the proinflammatory mediators contribute to septic shock is by stimulating tissue factor expression, which in turn activates the coagulation cascade $(37,41)$. In experimental animal models of gram-negative septic shock, a monoclonal antibody against tissue factor attenuates coagulopathy and protects against death (42).

Infectious endocarditis is characterized by the formation of valvular vegetations consisting of bacteria embedded within a platelet-fibrin meshwork. Tissue factor plays a key role in the development of these vegetations. From in vitro studies, it has been discovered that Staphylococcus aureus infection induces tissue factor synthesis and expression on endothelial cells and monocytes (43-45). While endothelial cells play an important role in the early events of vegetation formation, monocytes participate by intensifying fibrin deposition $(44,46)$. There is some controversy about the importance of live or killed bacteria in tissue factor induction $(45,47)$. Recently, it was demonstrated that the cell wall peptidoglycan of $S$. aureus induced tissue factor synthesis and expression on CD14-positive monocytes. The kinetics of tissue factor induction by LPS and peptidoglycan is similar, with maximal procoagulant activity developing within $4 \mathrm{~h}$. However, LPS is a 10-fold more potent stimulus of tissue factor expression compared to peptidoglycan (47).

Although $S$. aureus is able to induce endothelial cell tissue factor-mediated procoagulant activity in endothelial cells, other bacteria that cause infectious endocarditis, such as Streptococcus sanguis and Staphylococcus epidermitis, cannot (45). With these organisms, it is hypothesized that the formation of the vegetation is induced by tissue factor expressed by monocytes, rather than the endothelial cells.

Aspergillus fumigatus is an angioinvasive fungus, and invasive aspergillosis is characterized by vascular invasion with subsequent 
thrombosis and tissue infarction (48). We have developed an in vitro model of interaction of A. fumigatus with human umbilical vein endothelial cells (Lopes-Bezerra LM and Filler SG, unpublished results). Our data indicate that $A$. fumigatus stimulates endothelial cells to express tissue factor and become procoagulant. Candida albicans is another angioinvasive fungus. However, vascular thrombosis is not usually seen at foci of candidal infection. Interestingly, we found that $C$. albicans did not induce endothelial cell tissue factor activity in vitro. Similarly, in a patient with candidemia, it was found that the monocytes did not express tissue factor. In contrast, monocytes from patients with systemic bacterial infections strongly expressed tissue factor (49). These observations suggest that tissue factor expression is tightly controlled and is induced only in response to specific microbial pathogens.

In conclusion, activation of endothelial cell tissue factor-mediated procoagulant activity is a key event in the pathogenesis of several types of infection. Understanding this process and developing methods to control it hold great promise for improving the outcome of these severe and often fatal infections.

\section{References}

1. Drake TA, Morrissey JH \& Edgington TS (1989). Selective cellular expression of tissue factor in human tissues. Implications for disorders of hemostasis and thrombosis. American Journal of Pathology, 134: 1087-1097.

2. Wilcox JN, Smith KM, Shwartz SM \& Gordon D (1989). Localization of tissue factor in the normal vessel wall and in atherosclerotic plaque. Proceedings of the National Academy of Sciences, USA, 86: 2839-2843.

3. Fleck RA, Rao LV, Rapaport SI \& Varki SN (1990). Localization of human tissue factor antigen by immunostaining with monospecific, polyclonal anti-human tissue factor antibody. Thrombosis Research, 59: 421-437.

4. Nemerson $Y$ (1988). Tissue factor and hemostasis. Blood, 71: 1-8.

5. Morrissey JH (2001). Tissue factor: an enzyme cofactor and a true receptor. Thrombosis and Haemostasis, 86: 66-74.

6. Vallet B \& Wiel E (2001). Endothelial cell dysfunction and coagulation. Critical Care Medicine, 29 (Suppl 7): S36-S41.

7. Doshi SN \& Marmur JD (2002). Evolving role of tissue factor and its pathway inhibitor. Critical Care Medicine, 30 (Suppl 5): S241-S250.

8. Rottingen JA, Enden T, Camerer E, Iversen JG \& Prydz H (1995). Binding of human factor VIla to tissue factor induces cytosolic $\mathrm{Ca}^{2+}$ signals in J82 cells, transfected COS-1 cells, Madin-Darby canine kidney cells and in human endothelial cells induced to synthesize tissue factor. Journal of Biological Chemistry, 270: 4650-4660.

9. Poulsen LK, Jacobsen N, Sorensen BB, Bergenhem NC, Kelly JD, Foster DC, Thastrup O, Ezban M \& Petersen LC (1998). Signal transduction via the mitogen-activated protein kinase pathway induced by binding of coagulation factor VIla to tissue factor. Journal of Biological Chemistry, 273: 6228-6232.

10. Pendurthi UR \& Rao LV (2002). Factor VIla/tissue factor-induced signaling: a link between clotting and disease. Vitamins and Hormones, 64: 323-355.

11. Morrissey JH, Fakhrai H \& Edgington TS (1987). Molecular cloning of the cDNA for tissue factor, the cellular receptor for the initiation of the coagulation protease cascade. Cell, 50: 129-135.

12. Paborsky LR, Tate KM, Harris RJ, Yansura DG, Band L, McCray G, Gorman CM, O'Brien DP, Chang JY \& Swartz JR (1989). Purification of recombinant human tissue factor. Biochemistry, 28: 8072-8077.

13. Rapaport SI \& Rao LV (1995). The tissue factor pathway: how it has become a "prima ballerina". Thrombosis and Haemostasis, 74: 7-17.

14. Broze Jr GJ, Leykam JE, Schwartz BD \& Miletich JP (1985). Purification of human brain tissue factor. Journal of Biological Chemistry, 260: 10917-10920.

15. Stone MJ, Ruf W, Miles DJ, Edgington TS \& Wright PE (1995). Recombinant soluble human tissue factor secreted by Saccharomyces cerevisiae and refolded from Escherichia coli inclusion bodies: glycosylation of mutants, activity and physical characterization. Biochemical Journal, 310: 605-614.

16. Bevilacqua MP, Pober JS, Majeau GR, Contran RS \& Gimbrone MA (1984). Interleukin 1 (IL-1) induces biosynthesis and cell surface expression of procoagulant activity in human vascular endothelial cells. Journal of Experimental Medicine, 160: 618-623.

17. Edwards RL \& Rickles FR (1984). Macrophage procoagulants. Progress in Hemostasis and Thrombosis, 7: 183-209.

18. Meszaros K, Aberle S, Dedrick R, Machovich R, Horwitz A, Birr C, Theofan G \& Parent JB (1994). Monocyte tissue factor induction by lipopolysaccharide (LPS): dependence on LPS-binding protein and CD14, and inhibition by a recombinant fragment of bactericidal/ permeability-increasing protein. Blood, 83: 2516-2525.

19. Mantovani A, Bussolino F \& Introna M (1997). Cytokine regulation of endothelial cell function: from the molecular level to the bedside. Immunology Today, 18: 231-240.

20. Conway EM, Bach R, Rosenberg RD \& Konigsberg WH (1989). Tumor necrosis factor enhances expression of tissue factor mRNA in endothelial cells. Thrombosis Research, 53: 231-241.

21. Ameri A, Kuppuswamy MN \& Basu S (1992). Expression of tissue factor pathway inhibitor by cultured endothelial cells in response to inflammatory mediators. Blood, 79: 3219-3226.

22. Chan EL, Haudek SB, Giroir BP \& Murphy JT (2001). Human coronary endothelial cell activation by endotoxin is characterized by NFkappaB activation and TNF-alpha synthesis. Shock, 16: 349-354.

23. Diamant M, Nieuwland R, Pablo RF, Sturk A, Smit JW \& Radder JK (2002). Elevated numbers of tissue-factor exposing microparticles correlate with components of the metabolic syndrome in uncompli- 
cated type 2 diabetes mellitus. Circulation, 106: 2442-2447.

24. Le DT, Rapaport SI \& Rao LV (1992). Relations between factor VIla binding and expression of factor VIla/tissue factor catalytic activity on cell surfaces. Journal of Biological Chemistry, 267: 15447-15454.

25. Greeno EW, Bach RR \& Moldow CF (1996). Apoptosis is associated with increased cell surface tissue factor procoagulant activity. Laboratory Investigation, 75: 281-289.

26. Mulder AB, Smit JW, Bom VJ, Blom NR, Ruiters MH, Halie MR \& van der Meer J (1996). Association of smooth muscle tissue factor with calveolae. Blood, 88: 1306-1313.

27. Rao LV \& Rapaport SI (1988). Activation of factor VII bound to tissue factor: a key early step in the tissue factor pathway of blood coagulation. Proceedings of the National Academy of Sciences, USA, 85: 6687-6691.

28. Maruyama I (1998). Biology of endothelium. Lupus, 7 (Suppl 2): S41S43.

29. Broze Jr GJ (1992). The role of tissue factor pathway inhibitor in a revised coagulation cascade. Seminars in Hematology, 29: 159-169.

30. Broze Jr GJ (1995). Tissue factor pathway inhibitor and the current concept of blood coagulation. Blood Coagulation and Fibrinolysis, 6 (Suppl 1): S7-S13.

31. Grinnell BW \& Joyce D (2001). Recombinant human activated protein C: a system modulator of vascular function for treatment of severe sepsis. Critical Care Medicine, 29 (Suppl 7): S53-S58.

32. Esmon CT (2001). Protein C anticoagulant pathway and its role in controlling microvascular thrombosis and inflammation. Critical Care Medicine, 29 (Suppl 7): S48-S51.

33. Esmon CT, Fukudome K, Mather T, Bode W, Regan LM, StearnsKurosawa DJ \& Kurosawa S (1999). Inflammation, sepsis, and coagulation. Haematologica, 84: 254-259.

34. Healy DP (2002). New and emerging therapies for sepsis. Annals of Pharmacotherapy, 36: 648-654.

35. Kidokoro A, Iba T, Fukunaga M \& Yagi $Y$ (1996). Alterations in coagulation and fibrinolysis during sepsis. Shock, 5: 223-228.

36. Iba $T$, Kidokoro A \& Yagi $Y$ (1998). The role of the endothelium in changes in procoagulant activity in sepsis. Journal of the American College of Surgeons, 187: 321-329.

37. Esmon CT (1998). Inflammation and thrombosis. Mutual regulation by protein C. Immunologist, 6: 84-89.
38. Marshall JC (2001). Inflammation, coagulopathy, and the pathogenesis of multiple organ dysfunction syndrome. Critical Care Medicine, 29 (Suppl 7): S99-S106.

39. Bernard GR, Vincent JL, Laterre PF et al. (2001). Efficacy and safety of recombinant human activated protein $C$ for severe sepsis. New England Journal of Medicine, 344: 699-709.

40. Parrillo JE (1993). Pathogenic mechanisms of septic shock. New England Journal of Medicine, 328: 1471-1477.

41. van der Poll $T$, Büller HR, ten Cate $\mathrm{H}$, Wortel $\mathrm{CH}$, Bauer KA \& van Deventer SJH (1990). Activation of coagulation after administration of tumor necrosis factor to normal subjects. New England Journal of Medicine, 322: 1622-1627.

42. Taylor Jr FB, Chang A, Ruf W, Morrissey JH, Hinshaw L, Catlett R, Blick K \& Edgington TS (1991). Lethal E. coli septic shock is prevented by blocking tissue factor with monoclonal antibody. Circulatory Shock, 33: 127-134.

43. Bancsi MJLM, Thompson J \& Bertina RM (1994). Stimulation of monocyte tissue factor expression in an in vitro model of bacterial endocarditis. Infection and Immunity, 62: 5669-5672.

44. Veltrop MHAM, Thompson J \& Beekhuizen H (2001). Monocytes augment bacterial species- and strain-dependent induction of tissue factor in human vascular endothelial cells. Infection and Immunity, 69: 2797-2807

45. Veltrop MHAM, Beekhuizen H \& Thompson J (1999). Bacterial species- and strain-dependent induction of tissue factor in human vascular endothelial cells. Infection and Immunity, 67: 6130-6138.

46. Veltrop MHAM \& Beekhuizen $H$ (2002). Monocytes maintain tissue factor activity after cytolysis of bacteria-infected endothelial cells in an in vitro model of bacterial endocarditis. Journal of Infectious Diseases, 186: 1145-1154.

47. Mattsson E, Herwald H, Björck L \& Egesten A (2002). Peptidoglycan from Staphylococcus aureus induces tissue factor expression and procoagulant activity in human monocytes. Infection and Immunity, 70: 3033-3039.

48. Bodey GP \& Vartivarian S (1989). Aspergillosis. European Journal of Microbiology and Infectious Diseases, 8: 413-437.

49. Rivers RP, Cattermole HE \& Wright I (1992). The expression of surface tissue factor apoprotein by blood monocytes in the course of infections in early infancy. Pediatric Research, 31: 567-573. 